\title{
Outcome of an educational training programme on blood glucose monitoring among nurses in the management of hypoglycaemia and hyperglycemia
}

\author{
Patricia Obiajulu Onianwa ${ }^{1, A, C, E-F} \oplus$, Mary Oyenike Ayorinde ${ }^{1, B-D, F} \oplus$, \\ Folashade Omobisi Mary Akanbi ${ }^{1, B-D, F \oplus}$, Olufunke Olabisi Are ${ }^{1, B-C, F \oplus}{ }^{\infty}$, Alice Taiwo Nkom ${ }^{1, B, F \oplus}$, \\ Grace Oyeladun Akintola ${ }^{1, B, F}{ }^{\oplus}$, Adesola Gbenro-Ayodeji ${ }^{1, B-C, F}{ }^{-}$, Temitope Omowunmi Sodipo ${ }^{1, B, F} \oplus$, \\ Ogonna Eze Ojerinde ${ }^{1, B-C, F \oplus}$, Oladotun Eniola Ojemola ${ }^{1, B-C, F \oplus \infty}$ \\ 1 University College Hospital, Ibadan, Nigeria \\ A - Research concept and design, B - Collection and/or assembly of data, C - Data analysis and interpretation, \\ $D$ - Writing the article, E-Critical revision of the article, F- Final approval of article
}

Patricia Obiajulu Onianwa, Mary Oyenike Ayorinde, Folashade Omobisi Mary Akanbi, Olufunke Olabisi Are, Alice Taiwo Nkom, Grace Oyeladun Akintola, Adesola Gbenro-Ayodeji, Temitope Omowunmi Sodipo, Ogonna Eze Ojerinde, Oladotun Eniola Ojemola. Outcome of an educational training programme on blood glucose monitoring among nurses in the management of hypoglycaemia and hyperglycemia. J Pre-Clin Clin Res. 2021; 15(1): 20-25. doi: 10.26444/jpccr/132398

\begin{abstract}
I Abstract
Introduction. Diabetes mellitus is a chronic metabolic disorder that can lead to an increased length of hospital stay, delayed healing, and exacerbation of co-morbidities with complications arising if not properly managed. Better understanding and maintenance of normal blood glucose by nurses can positively influence care outcomes. The study aimed to assess nurses' knowledge on the management of diabetes and skills in blood glucose monitoring.

Materials and method. A structured pre- and post-questionnaire was used to assess nurses' knowledge on the management of diabetes, and a structured checklist was used to assess their skills in blood glucose monitoring. Three hundred and thirtyeight (338) participants directly involved in the provision of care to diabetic patients were randomly selected for the study. Data were analyzed using descriptive and inferential statistics.

Results. The study revealed that $58.9 \%$ of the respondents scored above the mean score of $33.1 \pm 3.5$ during pre-assessment, which shows they had a good baseline knowledge of blood glucose. A post-intervention finding showed $64.8 \%$ scored above the mean score of 36.3 3 3.1. Assessment of nurses' knowledge of blood glucose monitoring proficiency showed that $70.1 \%$ scored above the mean score of 11.4 .

Conclusions. The educational intervention programme with a practical training session was an effective method of approach for improving blood glucose management among the participants. However, it is recommended that protocols and practice guidelines should be placed at strategic locations, and methods of empowering nurses, such as providing them with equipment needed to sustain this practice, should be heightened.
\end{abstract}

\section{Key words}

hypoglycaemia, hyperglycaemia, management, nurses, blood glucose

\section{INTRODUCTION}

Diabetes is a chronic, debilitating, costly, and life-threatening disease affecting millions of people worldwide. It is a systemic endocrine disease caused by the inherited or acquired deficiency in the production of insulin by the pancreas, or by the ineffectiveness of the insulin produced, characterized by elevated levels of blood sugar [1]. In 2016, it was ranked as the 7th leading cause of death [2] and labeled an endemic disease affecting 425 million people worldwide, affecting both the young and old in society, threatening the health and economy of all nations $[3,4,5]$. Worldwide, the number of individuals with diabetes is growing at an unprecedented rate and is expected to surpass 550 million by 2030 [6]. In 1980, 1.8 million people were estimated to be living with diabetes;

Address for correspondence: Folashade Omobisi Mary Akanbi, University College Hospital, Queen Elizabeth Road, 21000 Ibadan, Nigeria

E-mail: shadeshayo2010@gmail.com

Received: 28.08.2020; accepted: 13.01.2021; first published: 05.02.2021 however, this number has risen to 422 million in 2014, with a $4.7 \%$ global prevalence among adults [2].

According to [5], in the Africa region, 15.9 million adults are living with diabetes, and the figure is estimated to increase to 41.6 million by 2045 . Also, 42.9 million adults in the African region have impaired glucose tolerance that places them at risk of type 2 diabetes, and a possible increase to 108.6 million in 2045. In addition to the estimated values, Africa has the highest percentage of undiagnosed diabetes, the estimated prevalence is $1 \%$ in rural areas and $5 \%-7 \%$ in the urban sub-Saharan region. The prevalence of diabetes is rapidly increasing in middle or low-income countries $[7,8]$. In sub-Saharan Africa, Nigeria has the highest number of people with diabetes, an estimated 3.9 million of the adult population aged 20-79 [9]. The prevalence of diabetes is $2 \%$, and $1,702,900$ of the population are living with diabetes [5]. According to the World Health Organization, the diabetes country profiles for 2016, numbers the deaths caused by diabetes in Nigeria at 27,830 in the age group 30-69-8,770 
males and 9,380 females aged 70 plus, males $-3,900$, females $-5,780[1]$.

According to [10], lack of adequate training of health care workers and lack of programmes to deliver quality diabetes education and training are major problems with diabetes management in the Sub-Saharan African region. Management of diabetes involves regular assessment and modification of a treatment plan by health care provider [11]. Nurses must possess the required knowledge and skills to achieve the goal of diabetes management. Nurses have a pivotal role to play in providing essential information to the patient to enable them to live a quality life. It is evidence from researches that a structured diabetic patient education on diabetes management and control has a positive effect on patient care devoid of complications $[12,13]$. If proper education is incorporated into the structured diabetics care programme in health care settings, more value will be added to patients' knowledge and self-care behaviours [14]. Therefore, nurses need to understand the new trends involved in the management of diabetes and the skills involved in blood glucose monitoring.

It is evidence from reported findings that the prevalence of diabetes globally is increasing rapidly, with 1 in 2 (232million) people with diabetes being undiagnosed [15]. This calls for the need to improve the knowledge of nurses on current practice guidelins in the management of diabetes and blood glucose monitoring for early identification and diagnosis of potential victims. A large number of health care workers were reported not to be familiar with the current practice guidelines in diabetes management. A study conducted in Rwanda reported that nurses had poor knowledge in the nutritional management of diabetes as well as pain management [16]. In Nigeria, studies from some states revealed that, in general, nurses have adequate knowledge on diabetes management,although deficiencies were identified in some aspects of care, including dietary management, exercises/activity, glucose monitoring, signs of acute complications of diabetes, and skin/foot care $[3,17$, $18,19]$. A better understanding of evidence-based practices by nurses involved in caring for individuals with diabetes can positively influence care outcomes, thereby reducing the risk of morbidity and mortality, as well as reducing outof-pocket expenditure.

Therefore, the aim of this study was to assess nurses' knowledge of the management of diabetes and proficiency in finger-prick blood glucose checks.

\section{MATERIALS AND METHOD}

The study has a pre-test and post-test single group design to assess the nurses' knowledge of the management of diabetes and skills in blood glucose monitoring. Three hundred and thirty-eight (338) nurses directly involved in the provision of care to diabetic patients, who also participated in a training programme on the use of the glucometer in the management of hypoglycaemia and hyperglycaemia, were randomly recruited and included in the study. The training was organized by the management of the institution in collaboration with the continuing education unit of the study setting. The study duration lasted throughout the training and covers for a period of seven months (April - October 2019). The study setting was a tertiary institution with the aim of research, training, and practice. The hospital has a staff of 1,340 nurses and is equipped with 970-bed spaces.

Approval for the study was obtained from the management of the institution. The confidentiality, autonomy, respect, and dignity of all the participants were strictly observed. Participants were assured of their rights to decline to participate in the study. A code number was assigned to each participant to maintain anonymity.

Educational package for the training on diabetes management and blood glucose check. The training programme aimed to improve nurses' knowledge of diabetes management, improve patient outcomes, and build nurses proficiency in performing blood glucose monitoring at the point of care. The training consists of two sections: a series of lectures and a clinical demonstration using an approved standard operating procedure for blood glucose checks. The training programme included focused education and group activities with individual instruction. Teaching materials included a training manual, glucometers, blood glucose strips, lancet, and a pen and pocket jotter for recording. The standardized procedure for blood glucose monitoring was followed as a guideline by every nurse during the practical sessions. The training package included lectures on:

- Overview of diabetes, hyperglycaemia, and hypoglycaemia.

- Importance of routine blood glucose monitoring.

- Self-monitoring of blood glucose in the management of diabetes.

- Point of care of blood glucose check.

- Standard operating procedure for a blood glucose check.

Data Collection. Data was collected using 17 structured items, a self-administered questionnaire, and a structured step by step procedure checklist to assess proficiency in the finger-prick blood glucose check. Both instruments were developed using a training manual and extensive literature reviewed. The questionnaire consisted of 2 sections: 1 ) assessed the demographic data of the participants, 2) consisted of 14 items that assessed each nurse's knowledge of diabetes, management, and glycaemic control. The content of the instrument was validated by experts in diabetes management, and the reliability of the instrument was tested using the Cronbach Alpha test with a result of 0.81 .

Proficiency assessment using a checklist. A structured checklist was used to assess the participant's skills in performing a finger-prick blood glucose check. It consists of 14 items of the standard operating procedure protocol for checking fingerprick blood glucose. The protocol includes an explanation of the procedure to the patient, handwashing before the procedure, maintaining a comfortable position for the patient, removing the strip from the container and inserting it into the glucometer, cleaning with a methylated spirit swab the area to be pricked, and allowing the area to dry well before pricking, using the sides of the fingers rather than the pulp as they are less sensitive and less likely to cause pain, pricking with a lancet or lancing device equipped with a lancet, gently pressing along the finger to aid blood flow, applying enough blood on the strip to cover the marked area, applying a small piece of cotton wool or gauze to the puncture site, disposing of the lancet in a sharp box, hand washing after the procedure, documenting the result on the appropriate form on the patient's chart, and reporting abnormal results to the investigator. 
Data Analysis. The assessment checklist and the survey questionnaire were scored manually, entered into SPSS version 22.0 software, and reviewed for data entry accuracy. Descriptive statistics summarized the data. The normality was checked for the quantitative variables, such as pre- and post-knowledge scores. Parametric statistics paired t-test was used to compare the pre- and post-knowledge score, while non-parametric statistics, chi-square, was used to find the association between the post-training score, years of experience, and proficiency in blood glucose monitoring. Questions on knowledge and checklist proficiency were scored and dichotomized into adequate and inadequate, using the mean score as a yardstick for categorization.

\section{RESULTS}

A total number of 1,310 nurses were trained in the use of a glucometer in the management of hypoglycaemia and hyperglycaemia, of which 338 nurses who were providing direct care to diabetic patients were randomly selected for the study. The results showed that the mean age of the participants was $39.7 \pm 8.8$ (Tab. 1). The majority of the participants were females (95.9\%) and $55.7 \%$ had more than 10 years work experience.

Table 1. Demographic characteristics of respondents

\begin{tabular}{|c|c|c|}
\hline Variable & $\mathrm{n}(\%)$ & Percentage(\%) \\
\hline Age group (yrs: Mean \pm SD): & $39.7 \pm 8.8$ & \\
\hline Below 26 & 4 & 1.2 \\
\hline $26-35$ & 133 & 39.3 \\
\hline $36-45$ & 108 & 32.0 \\
\hline Above 45 & 93 & 27.5 \\
\hline \multicolumn{3}{|l|}{ Gender: } \\
\hline Male & 14 & 4.1 \\
\hline Female & 324 & 95.9 \\
\hline \multicolumn{3}{|l|}{ Educational qualification: } \\
\hline Diploma in Nursing & 123 & 36.4 \\
\hline BNSC & 184 & 54.4 \\
\hline MSc (Nursing and other related field) & 26 & 7.7 \\
\hline Other & 5 & 1.5 \\
\hline \multicolumn{3}{|l|}{ Years of experience: } \\
\hline $1-5$ & 62 & 18.3 \\
\hline $6-10$ & 88 & 26.0 \\
\hline $11-15$ & 55 & 16.3 \\
\hline 16 and above & 133 & 39.4 \\
\hline \multicolumn{3}{|l|}{ Professional cadre: } \\
\hline Nursing Officer II (NOII) & 79 & 23.4 \\
\hline Nursing Officer I (NOI) & 94 & 27.8 \\
\hline Senior Nursing Officer (SNO) & 22 & 6.5 \\
\hline Assistant Chief Nursing Officer (ACNO) & 19 & 5.6 \\
\hline Chief Nursing Officer (CNO) & 86 & 25.4 \\
\hline Assistant Director of Nursing (ADN) & 32 & 9.5 \\
\hline Director of Nursing (DDN) & 6 & 1.8 \\
\hline
\end{tabular}

The study revealed that $58.9 \%$ of the respondents scored above the mean score of $33.1 \pm 3.5$ during pre-assessment, which shows they had good baseline knowledge of blood glucose. The post-intervention finding showed that $64.8 \%$ scored above the mean score of $36.3 \pm 3.1$ (Fig. 1). Assessment of nurses' knowledge on blood glucose monitoring proficiency, shows that $70.1 \%$ scored above the mean score of 11.4 (Fig. 2).

The majority of the nurses - 255 (75.4\%), correctly stated that less than $50 \mathrm{mg} / \mathrm{dl}$ is considered as hypoglycaemia in a person who does not have diabetes post-intervention, while

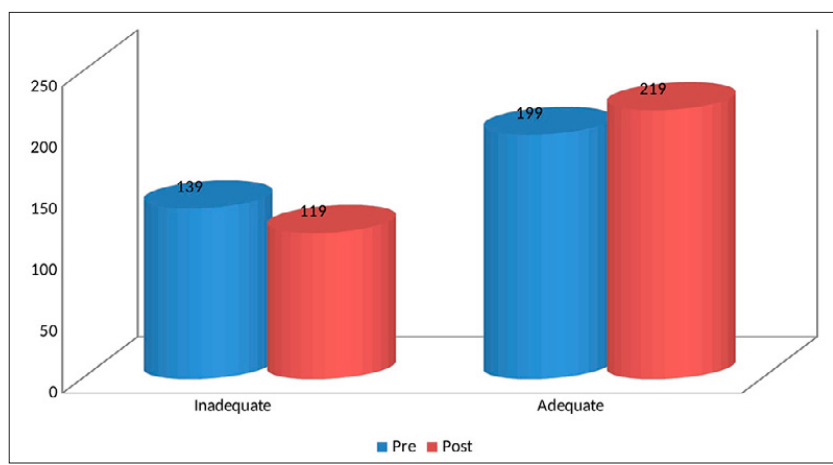

Figure 1. Pre and Post training knowledge evaluation on BGL

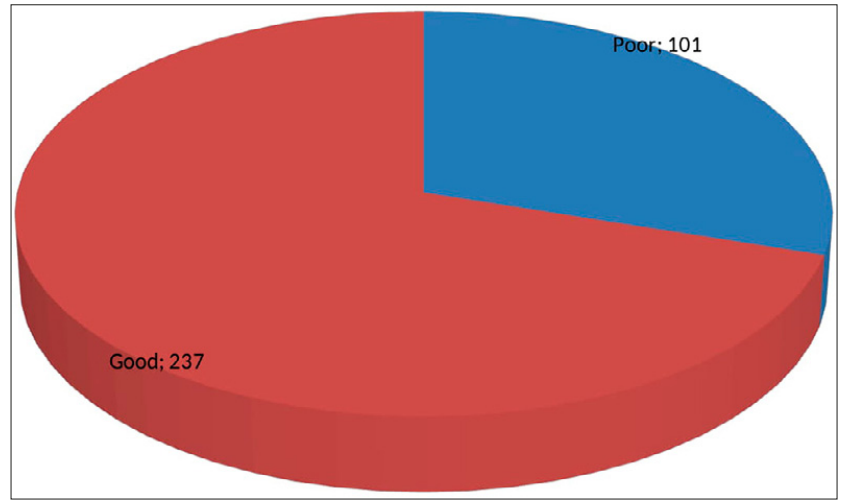

Figure 2. Post training evolution askills on BGL monitiring

$222(65.7 \%)$ were correct in the pre-intervention. $256(75.7 \%)$ of the nurses in the post-intervention correctly stated that less than $70 \mathrm{mg} / \mathrm{dl}$ is considered as hypoglycaemia in a known diabetic patient, compared to $229(67.8 \%)$ in pre-intervention. $115(63.6 \%)$ of the nurses in the post-intervention correctly stated fasting hyperglycaemia is considered as a blood glucose level of $>130 \mathrm{mg} / \mathrm{dl}$, while 203 (60.1\%) were correct in pre-intervention. 319 (94.4\%) stated that post-prandial hyperglycaemia is considered at a blood glucose level of $>180 \mathrm{mg} / \mathrm{dl}$ post-intervention, compared to 280 (82.8\%) preintervention (Tab. 2)

All $100.0 \%$ of the respondents claimed that the blood glucose level can be altered by the following factors: food intake, exercise, medications, illness, stress, alcohol, pregnancy, and age at the post-intervention stage, while about $92.0 \%$ were able to identify these in pre-intervention. Also, $87.0 \%$ and over $99 \%$ of participants in the pre- and post-assessment identified cardiac arrhythmia, seizures, permanent neurologic deficit, and death as complications of severe hypoglycaemia. The respondents had adequate pretraining knowledge of blood glucose monitoring in stable patients, but some patients received intravenous insulin and sub-cute insulin. Post-training assessment shows an improvement in knowledge of blood glucose monitoring (Tab. 2).

The study revealed that only $5.3 \%$ of the participants could correctly define the point of care blood glucose check, 53.8\% could define correctly 15-15 rules of glycaemic control, and the majority were able to correctly identify the red flags for hypoglycaemia and hyperglyacemia during the preassessment. The vast majority of nurses during the pre- and post-assessment reported the following as factors increasing the risk of blood glucose instability: failure to make the appropriate adjustment to therapy as or when due, poor 
Table 2. Participants knowledge on patients' glucose level

\begin{tabular}{|c|c|c|c|c|}
\hline \multirow[t]{2}{*}{ Response } & \multicolumn{2}{|c|}{ Pre-test } & \multicolumn{2}{|c|}{ Post-test } \\
\hline & Correct n(\%) & Incorrect n(\%) & Correct n(\%) & Incorrect $\mathrm{n}(\%)$ \\
\hline Hyperglycaemia is a primary implication for inpatient care & $252(74.6)$ & $86(25.4)$ & 284(84.0) & $54(16.0)$ \\
\hline$<50 \mathrm{mg} / \mathrm{dl}$ is considered as hypoglycaemia in a person who do not have diabetes & $222(65.7)$ & $116(34.3)$ & $255(75.4)$ & $83(24.6)$ \\
\hline$<70 \mathrm{mg} / \mathrm{dl}$ is considered as hypoglycemia in a known diabetic patients & $229(67.8)$ & $109(32.2)$ & $256(75.7)$ & $82(24.3)$ \\
\hline Fasting hyperglycaemia is considered blood glucose $>130 \mathrm{mg} / \mathrm{dl}$ & 203(60.1) & 135(39.9) & 215(63.6) & $123(36.4)$ \\
\hline \multicolumn{5}{|l|}{ Factors that alter blood glucose level: } \\
\hline Food intake & $333(98.5)$ & $5(1.5)$ & $337(99.7)$ & $1(0.3)$ \\
\hline Exercise & $290(85.8)$ & $48(14.2)$ & 337(99.7) & $1(0.3)$ \\
\hline Medications & $334(98.8)$ & $4(1.2)$ & $338(100.0)$ & $0(0.0)$ \\
\hline Illness & $324(95.9)$ & $14(4.1)$ & $337(99.7)$ & $1(0.3)$ \\
\hline Stress & $310(91.7)$ & $28(8.3)$ & $338(100.0)$ & $0(0.0)$ \\
\hline Alcohol & $328(97.0)$ & $10(3.0)$ & $335(99.1)$ & $3(0.9)$ \\
\hline Pregnancy & $320(94.7)$ & $18(5.3)$ & $334(98.8)$ & $4(1.2)$ \\
\hline \multicolumn{5}{|l|}{ Complications of severe hypoglycaemia: } \\
\hline Cardiac arrhythmia & $287(84.9)$ & $51(15.1)$ & $336(99.4)$ & $2(0.6)$ \\
\hline Seizures & $280(82.8)$ & $58(17.2)$ & $337(99.7)$ & $1(0.3)$ \\
\hline Permanent neurologic deficit & $272(80.5)$ & $66(19.5)$ & $337(99.7)$ & $1(0.3)$ \\
\hline Death & $332(98.2)$ & $6(1.8)$ & $337(99.7)$ & $1(0.3)$ \\
\hline \multicolumn{5}{|l|}{ Adequate blood glucose monitoring by a nurse in a diabetes patient must be: } \\
\hline $\begin{array}{l}\text { ideally performed before and after meal, and at bedtime, in most in-patients who } \\
\text { are eating usual meal + PRN. }\end{array}$ & $307(90.8)$ & $31(9.2)$ & $332(98.2)$ & $6(1.8)$ \\
\hline Patients receiving IV insulin infusion should have hourly blood glucose check. & $180(53.3)$ & 158(46.7) & $230(68.0)$ & 108(32.0) \\
\hline NPO patients receiving S.C. insulin should have 6-hourly blood glucose check + PRN. & $168(49.7)$ & $170(50.3)$ & 205(60.7) & $133(39.3)$ \\
\hline The point of care blood glucose check & $18(5.3)$ & $320(94.7)$ & $138(40.8)$ & 200(59.2) \\
\hline \multicolumn{5}{|l|}{ The point of care blood glucose check is essential because: } \\
\hline it provides information on the pattern of blood glucose at different time of the day. & $315(93.2)$ & 23(6.8) & $332(98.2)$ & $6(1.8)$ \\
\hline Helps to identify if symptoms experienced are due to low or high blood glucose. & $331(97.9)$ & $7(2.1)$ & $333(98.5)$ & $5(1.5)$ \\
\hline Facilitates appropriate intervention/ adjustment of treatment & $333(98.5)$ & $5(1.5)$ & $337(99.7)$ & $1(0.3)$ \\
\hline \multicolumn{5}{|l|}{ Red flag for hypoglycaemia include: } \\
\hline Headache & 294(87.0) & $44(13.0)$ & $327(96.7)$ & $11(3.3)$ \\
\hline Hunger & $311(92.0)$ & $27(8.0)$ & $331(97.9)$ & $7(2.1)$ \\
\hline Shaking & $324(95.9)$ & $14(4.1)$ & $334(98.8)$ & $4(1.2)$ \\
\hline Sweating & $332(98.2)$ & $6(1.8)$ & $336(99.4)$ & $2(0.6)$ \\
\hline Feeling tired or weak & $335(99.1)$ & $3(0.9)$ & $334(98.8)$ & $4(1.2)$ \\
\hline Grouchy mood, getting irritated easily & $253(74.9)$ & $85(25.1)$ & $326(96.4)$ & $12(3.6)$ \\
\hline \multicolumn{5}{|l|}{ Red flag for hyperglycaemia: } \\
\hline Drowsiness/decreased alertness & 292(86.4) & $46(13.6)$ & $319(94.4)$ & 19(5.6) \\
\hline Unquenchable thirst & $315(93.2)$ & 23(6.8) & $319(94.4)$ & 19(5.6) \\
\hline Frequent urination & $322(95.3)$ & $16(4.7)$ & $320(94.7)$ & $18(5.3)$ \\
\hline Increase heart rate & $307(90.8)$ & $31(9.2)$ & $320(94.7)$ & $18(5.3)$ \\
\hline Nausea and vomiting & $219(64.8)$ & $119(35.2)$ & $266(78.7)$ & $72(21.3)$ \\
\hline \multicolumn{5}{|l|}{ Factors increasing the risk of blood glucose instability: } \\
\hline failure to make appropriate adjustment to therapy as at when due. & $335(99.1)$ & $3(0.9)$ & $334(98.8)$ & $4(1.2)$ \\
\hline Poor coordination of blood glucose testing. & $325(96.2)$ & $13(3.8)$ & $335(99.1)$ & $3(0.9)$ \\
\hline Poor communication between managing team. & $312(92.3)$ & $26(7.7)$ & $337(99.7)$ & $1(0.3)$ \\
\hline Financial instability. & $320(94.7)$ & $18(5.3)$ & $330(97.6)$ & $8(2.4)$ \\
\hline
\end{tabular}

coordination of blood glucose testing, poor communication between the managing team, and financial instability.

The mean $\pm S D$ of pre-training knowledge of blood glucose level was $33.1 \pm 3.5$, compared to $36.3 \pm 3.1$ of post-training (Table 3). It can be seen that there was a significant difference

Table 3. Difference in pre- and post-educational intervention

Hypotheses Testing - Hypothesis One $\left(\mathbf{H}_{01}\right)$ : There was no significant difference between the pre- and post-knowledge score

\begin{tabular}{lcccc}
\hline Stage & Mean & SD & t-score & p-value \\
\hline Pre-educational intervention & 33.1 & 3.5 & & \\
Post-educational intervention & 36.3 & 3.1 & 3.22 & 0.001 \\
\hline
\end{tabular}

$(t=3.22 ; p=0.001)$ in the methods for evaluating pre-training and post-training knowledge. The post-training knowledge of the participant was not significantly $(X 2=0.73 ; p=0.46)$ associated with their post-training proficiency of checking finger-prick blood glucose level (Tab. 4). Besides, the years of experience of the participant was not significantly $(X 2=$ $3.59 ; p=0.31$ ) associated with the proficiency of checking the finger-prick blood glucose level. 
Table 4. Cross-tabulation between years of experience and proficiency in blood glucose level check

Hypothesis Testing - Hypothesis Two $\left(\mathbf{H}_{02}\right)$. There was no significant association between years of experience and proficiency in blood glucose level check.

\begin{tabular}{lccccccc}
\hline $\mathrm{H}_{02}$ & $\begin{array}{c}\text { Proficiency of BGL } \\
\text { check }\end{array}$ \\
\hline Years of & $1-5$ & $23(22.8)$ & $39(16.5)$ & 3 & 3.59 & 0.31 & Not \\
experience & $6-10$ & $29(28.7)$ & $59(24.9)$ & & & & Significant \\
& $11-15$ & $16(15.8)$ & $39(16.5)$ & & & \\
& $16+$ & $33(32.7)$ & $100(42.2)$ & & & \\
& Total & 101 & 237 & & & \\
& & & & & \\
& & & & & & & \\
& & &
\end{tabular}

\section{DISCUSSION}

Nurses play a significant role in the round-the-clock care of patients with diabetes. Hence, they must understand blood glucose monitoring and management to support and give continuous quality care to the patients. Socio-demographic characteristics of the participants revealed that the majority of the nurses were female (95.9\%), aged $26-35$ years (39.3\%), and $39.4 \%$ of them had more than 16 years work experience.

Overall, the knowledge of nurses about diabetes and glycaemic control in this study population was good, the majority $-58.9 \%$, scored above the mean score in the pre-test and $64.5 \%$ in the post-test. The study also shows a significant difference in the pre- and post-training knowledge score with $\mathrm{p}$-value $=0.001$. This result is consistent with a recent study evaluating nurse's knowledge which showed that the test scores increased significantly from pre- to posttraining after a diabetes educational training programme $[20,21]$. Previous studies affirmed that nurses' knowledge of diabetes management improved after receiving an educational intervention package on diabetes management intervention $[22,23,24]$. On the contrary, a study carried out in Jordan and Libya among registered nurses, and a systematic review carried out among nurses in different countries, the overall results indicated general deficiencies in nurses' knowledge of diabetes and diabetes care $[22,24,25]$. The knowledge level of nurses on diabetic management and creating a balance on the glycaemic index among diabetes patients cannot be over-emphasized. Studies revealed that more than medication adherence is needed to improve and achieve good glycaemic control in these patients [26, 27]. Nurses who are knowledgeable and competent are essential in providing quality, cost-effective diabetes care to improve patient outcomes. As nurses' knowledge improves, patient education and outcomes also improve. Nurses must therefore be up-to-date with current evidence-based information on improving glycaemic control for better patient outcomes [28].

Another very important area in which the nurses lacked knowledge was the correct meaning of a point of care blood glucose check. Only $5.3 \%$ of the participants gave the correct meaning of point of care blood glucose check pre-assessment, and $40.8 \%$ post-assessment. Studies in Australia, India, and Rwanda identified medication management, foot care and nutrition, as well as pain management, as the weakest knowledge areas among the nurses' studies [3, 16, 29]. The reason for the poor performance in their response to the point of care glucose check questions might be related to the low understanding of the term. Nurses need to fully understand the meaning and purpose of point of care blood glucose check for early recognition and identification of the classic symptoms of hyperglycaemia and hypoglycaemia. It is a crucial strategy for prevention and provision of quality management in the case of an emergency. Therefore, the role of continuing education cannot be ignored, it is essential in supporting nurses' knowledge of complex clinical conditions such as diabetes. It is also relevant for the implementation and dissemination of evidence-based guidelines in caring for people with diabetes by nurses, as a prerequisite for improving their knowledge.

The assessment of nurses proficiency in the use of the approved standard operating procedure to monitor blood glucose was through the finger prick method. A great number of nurses $(70.1 \%)$ scored above the mean score of 11.4. This finding is similar to a survey conducted in Australia in which $71.9 \%$ of the participants' demonstrated good performance of finger-prick blood glucose check [30]. Their performance can be attributed to the act of nursing practices which is task-oriented, allowing the participants to demonstrate the step-by-step guidelines for the standard operating procedure for a finger-prick blood glucose check.

This study also found no significant association between years of experience and proficiency in checking blood glucose levels. This was consistent with the findings of [18] where no significant correlation was found between years of experience and knowledge scores of nurses. This is also in accordance with a study in Jordan where the years of nursing experience had no significant association with actual level of knowledge [24]. Similarly, studies on the extent of knowledge regarding dietary advice to diabetes patients revealed that there was no significant correlation between years of experience and the nutritional knowledge of nurses [3,31]. All the above-findings infer that years of experience do not guarantee exceptional knowledge on blood glucose monitoring and management.

Continuing education can positively empower nurses to be skillful in providing an adequate point of care support to detectable and non-detectable cases. It was discovered in this study that even after the training, more than 50\% of the participant could not define correctly what a point of care blood glucose check care is. It is therefore essential that all nurses on all units have a basic knowledge of caring for diabetes patients at the point of care to identify gaps in patients' knowledge that calls for urgent intervention, avoiding further complications, and also assist in maintaining good glycaemic control for quality patient outcomes.

Creating a continuous supportive environment for learning may empower nurses to make the best-informed healthcare decisions. It is evident from this study that there is a significant improvement in the participant baseline knowledge score after the post-training evaluation. Nurse's knowledge hypoglycaemia and hyperglycaemia are important and beneficial to support evidence that blood glucose monitoring and management must be improved in the hospital setting to ensure prompt interventions or treatments that can benefit the patient, prevent additional days of hospitalization, and increase the burden of care and mortality ratio. 


\section{CONCLUSIONS}

The results of this study indicate that the participants were well-informed about diabetes management, comparing the baseline scores with post-assessment scores, which can be associated with their area of practice. The study proves that the nurses were able to demonstrate proficiency in checking the finger pricked blood glucose level by accurately using a glucometer. Lastly, the information acquired from the educational intervention programme was seen to have improved their knowledge of diabetes management.

The routine identification of gaps in knowledge gaps highlight the areas necessary for future educational in-service training must be identified to improve diabetes management to meet with current worldwide trends.

\section{Acknowledgment}

The authors express their appreciation to all the nurses who participated in the training and the study, as well as the management in the study setting.

\section{REFERENCES}

1. World health organization. Diabetes country profile. 2016. Retrieved from http://www.who.int

2. World health organization. Global report on diabetes. 2018. Retrieved from http://www.who.int

3. Ghani M, Akhtar T, Shuaib N, et al. Female Nurses Knowledge regarding Dietary Advice to type II Diabetes patients. Israel Med J. 2018; 10(4): 239-243.

4. Burke SD, Sherr D, Lipman, RD. Partnering with diabetes educators to improve patient outcomes. Diab Metabol Syndrome Obses. 2014; 7: 45-53. https://doi.org /10.2147/DMSO.S40036

5. International Diabetes Federation. IDF Diabetes Atlas, 8th ed. Diabetes in Africa. 2017. Retrieved from http://www.diabetesatlas.org

6. International Diabetes Federation. IDF Diabetes Atlas, 7 ed. 2013. Retrieved from http://www.diabetesatlas.org

7. Ogbera AO, Ekpebegh C. Diabetes mellitus in Nigeria, the past, present, and future. World J Diabet. 2014; 15:5(6): 905-911. https:// doi.org/10.4239/wjd.v5.i6.905

8. Oguejofor O, Odenigbo C, Onwukwe C. Diabetes in Nigeria, impact, challenges, future directions. Endocrinol Metab Synd. 2014; 3:130. https://doi.org/10.4172/2161-1017.10000130

9. Dahiru K, Aliyu AA, Shehu AU. A review of population-based studies of diabetes mellitus in Nigeria. Sub-Saharan Africa J Med. 2016; 3(2): 59-64. Retrieved from http://doi.org/10.4103/2384-5147.184351

10. Alebiosu OC, Familoni OB, Ogunsemi OO, et al. Knowledge of diabetes and hypertension care among health care workers in southwest Nigeria. Postgraduate Med. 2009; 121(1): 173-177. https://doi.org/10.3810/ pgm.2009.01.1965

11. Mohammed AH. "Bringing diabetes under control”. Bringing diabetes under control. 2013. Retrieved from https://ezinearticles.com.

12. Funnel MM, Brown TL, Childs BP, et al. National standards for diabetes self-management education. Am Diab Assoc. 2011; 34(1): s89-s96. https://doi.org/102337/dc11-s089.

13. Essien O, Out A, Umoh V, et al. Intensive patient education improves glycemic control in diabetes compared to conventional education: a randomized controlled trial in a Nigerian tertiary care hospital. PLoS ONE. 2017; 12(1). doi: 10.137/journal.pone.0168835

14. Jasper US, Ogundunmade BG, Opara MC, et al. Determinant of diabetes knowledge in a cohort of Nigerian diabetics. Journal Diabetes Metab Disord. 2014; 13(1): 39. https://doi.org/10.1186/2251-6581-13-39

15. International Diabetes Federation. Diabetes Facts and Figures. IDF Diabetes Atlas 9th Edition. 2019. Retrieved from http://www. diabetesatlas.org

16. Bagweneza V, Musabirema P, Mwiseneza MJ, et al. Diabetes health education: Nurses' knowledge of essential componenets at a Rwanda Hospital. Rwanda J Med. Health Sci. 2019; 2(2). https://doi.org/10.4314/ rjmhs.v2i2.13

17. Oyetunde MO, Famakinwa TT. Nurse's knowledge of contents of diabetes patient education in Ondo State, Nigeria. J Nurs Educ Practice. 2014; 4(4). https://doi.org/doi/10.5430/jnep.v4n4p91

18. Odili VU, Eke I. Knowledge of Diabetes Mellitus among Registered Nurses in Benin City. Int J Health Res. 2010; 3(3), 145-151. https://doi. org/10.4314/ijhr.v3i3.70299

19. Yacoub MI, Demeh WM, Barr, JL, et al. Outcome of diabetes education program for registered nurses caring for individual with diabetes. J Contin Edu Nurs. 2015; 46(3): 129. https://doi.org/10.3928/00220124/2015012602 .

20. Abduzhapparova A. Implementation of the educational program on diabetes mellitus type 2 for nurses' primary health care (Master's thesis, JAMK University of Applied Sciences, Jyvaskyla, Finland.). 2019. Retrieved from https://www.theseus.fi/bitstream/ handle/10024/22768520

21. Holmes C, Dyer P. Diabetes training for nurses: The effectiveness of an inpatient diabetes half-day workshop. Journal of Diabetes Nursing. 2013; 7(3): 86-94. Retrieved from https://www.diabetesonthenet.com.

22. Abduelkarem A, El-ShareifH. Assessment of diabetes-related knowledge among nursing staff in a hospital setting. J Diab Nurs. 2013; 17(8): 207-218. Retrieved from https://www.the journal diabetesnursing. co.uk/media/content

23. Modic M, Vanderbilt A, Siedlecki S, et al. Diabetes management unawareness: What do bedside nurses know? Applied Nurs Res. 2013; 27: 157-161. https://doi.org /10.2337/dc12-2430.

24. Yacoub M, Demeh W, Darawad M. et al. An assessment of diabetesrelated knowledge among registered nurses working in hospitals in Jordan, International Nursing Review. 2014; 61: 255-262. https://doi. org /10.1111/inr.12090

25. Alotaibi A, Al-Ganmi A, Gholizadeh L, Perry L. Diabetes knowledge of nurses in different countries: An integrative review. Nurse Education Today. 2016; 39: 32-49. https://doi.org/10.1016/j.nedt.2016.01.017

26. Tricco A, Ivers N, Grimshow J, Moher D. Effectiveness of quality improvement strategies on the management of diabetes. Sci Direct. 2012; 379(22): 52-61. https://doi: 10.1016/50140-6736(12)60480-z

27. Williams J, Walker R, Smalls B, Campbell J, Egede L. Effective interventions to improve medication adherence in type 2 diabetes. Diab Management. 2014; 4(1): 29-48. https://doi: 10.2217/dmt.13.62

28. Coffey A. The impact of diabetes education on nurses' knowledge of inpatient diabetes management (Doctoral dissertation, Regis University). 2016. Retrieved from https://epublications.regis.edu/theses/801

29. Hollis M, Glaister K, Lapsley JA. Do practice nurses have the knowledge to provide diabetes self-management education? Contemporary Nurse. 2014; 46(2): 234-241. https://doi.org/10.5172/conu.2014.46.2.234

30. Waheed N. Nurses' knowledge of blood glucose levels and the management of hypoglycaemia and hyperglycemia: A descriptive study. Madridge J Nurs. 2017; 2(1): 56-62. https://doi.org /10.18689/ mjn.2017-110

31. Naseem MA, Areej BS, Abdallah SA, et al. Assessment of Therapeutic Nutritional Knowledge of Jordanian Nurses. Int J Nutrit Food Sci. 2013; 2 (3): 142-148. https://doi.org/10.11648/j.ijnfs.20130203.18 